\title{
Serum prolactin levels in undernourished Indian lactating women
}

\author{
BY VEENA SHATRUGNA, NAMALA RAGHURAMULU \\ AND KRISHNAMURTHY PREMA \\ National Institute of Nutrition, Indian Council of Medical Research, \\ Jamai-Osmania (PO), Hyderabad - 500 007, India
}

\section{(Received 28 August 1981-Accepted 25 February 1982)}

1. Serum prolactin (PRL) levels, both basal and post-suckling peak, were estimated in fifty-seven lactating women.

2. Basal PRL levels were significantly higher in all lactating women irrespective of the duration of lactation as compared to the levels in non-pregnant, non-lactating women.

3. There was a significant positive correlation $(r 0.69, P<0.001)$ between the basal PRL levels and the post-suckling peak values.

4. After 8 months of lactation, peak post-suckling, PRL levels were not significantly different from basal values.

5. Basal PRL levels were significantly lower $(P<0.05)$ in mothers whose infants were being supplemented.

6. PRL levels were not related to the mother's nutritional status as determined by body-weight.

7. The findings suggest that high PRL levels during lactation prolong the duration of lactional amenorrhoea and hence the relative infertility.

Epidemiological and laboratory investigations indicate that lactation prolongs post partum amenorrhoea and provides some protection against pregnancy (Gioiosa, 1955; Bonte \& Van Balen, 1969; Population Reports, 1975; Prema et al. 1979). Some studies also indicate that the duration of unsupplemented lactation is the critical determinant of duration of lactational amenorrhoea (Perez et al. 1972; Chen et al. 1974) and recent investigations also suggest that maternal nutritional status, as assessed by body-weight, might also have some effects on the duration of lactational amenorrhoea (Prema et al. 1979; Lunn et al. 1980; Prema, Naidu et al. 1981). It is believed that the effect of lactation on lactational amenorrhoea is mediated through prolactin (PRL; McNeilly, 1979) but there is little information available on plasma PRL levels in undernourished lactating women in relation to their breast-feeding practices and nutritional status.

A study was therefore undertaken to investigate plasma PRL levels in undernourished lactating women in relation to: $(a)$ breast-feeding practices, $(b)$ duration of lactation, $(c)$ return of menstruation and $(d)$ maternal body-weight.

\section{MATERIALS AND METHODS}

Subjects. Sixty-four women volunteered for this study, fifty-seven of whom were lactating successfully between 3 weeks and 1 year post partum seven were non-pregnant, non-lactating (NPNL) and regularly menstruating. All the women belonged to low-income groups (per capita income (Rs./month) between 30 and 120). The mean age was 24.3 years and mean parity 2.49 . Mean height was $1.498 \mathrm{~m}$ and weight $44.09 \mathrm{~kg}$. Diet surveys using a $24 \mathrm{~h}$ dietary-recall method in a similar group of women attending the out-patient department have shown that the mean energy intake is not more than $5.86 \mathrm{MJ} / \mathrm{d}(1400 \mathrm{kcal} / \mathrm{d})$ and that diets are deficient with respect to most nutrients. These women lose approximately $2 \mathrm{~kg}$ in weight over the first 12 months of lactation and slowly regain body-weight to values comparable with those found in NPNL women, over the next 12 months (Prema, Madhavapadi et al. 1981). In the present study, the mothers came to the hospital for immunization of their children or accompanying a sick relative. In this community infants 


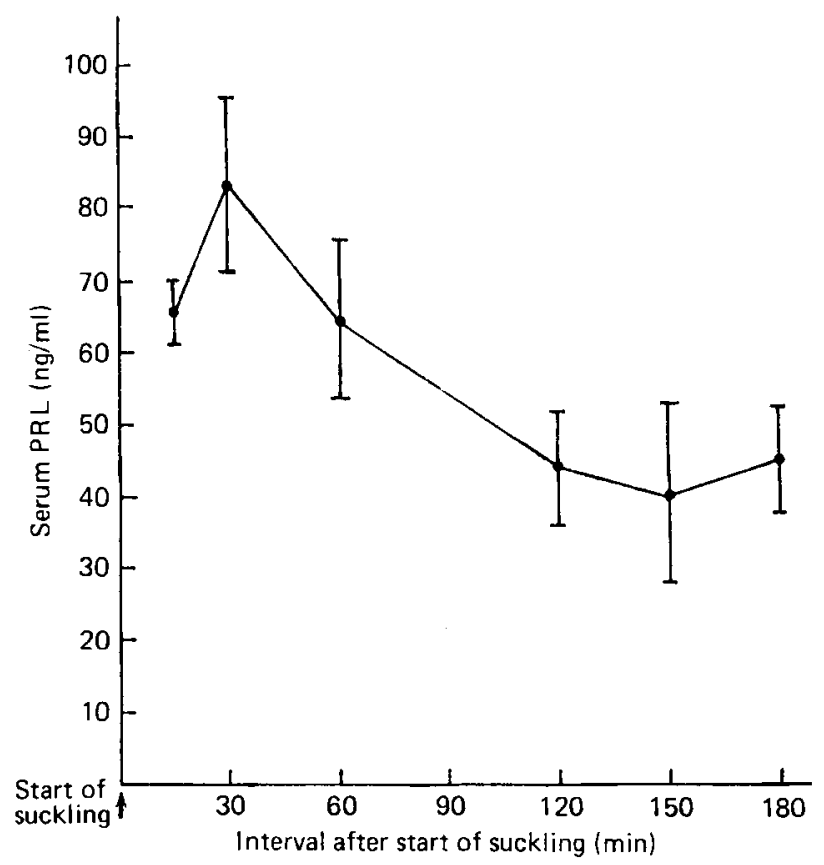

Fig. 1. Serum prolactin (PRL) levels $(\mathrm{ng} / \mathrm{ml}$ ) at various intervals (min) after start of suckling in undernourished Indian women. Points are mean values with their standard errors represented by vertical bars.

are fed on demand and are usually suckled more than ten times daily. Supplemented children usually receive small quantities of dilute cow's milk, a cereal gruel, mashed banana, biscuits, or one of the processed cereals, at great cost to the mother. Because of operational problems attempts were not made to obtain information regarding milk output, quantity of supplements, their contribution to nutrient intake of the infant, and the effect of supplements on frequency and duration of suckling, but information on the duration of lactation and whether supplements were introduced was obtained in all cases. Details regarding the duration of lactational amenorrhoea and menstrual history during lactation was also obtained. The subjects were given appointments such that on their subsequent visit they reached the hospital $2 \mathrm{~h}$ after breast-feeding the child. This fact was confirmed before basal blood samples were drawn $0.5 \mathrm{~h}$ after their arrival $(2.5 \mathrm{~h}$ after the last feed). Mothers unable to comply were given a fresh appointment. The baby was then put to the breast for 10-15 min. The mothers' and babies' weights were also recorded. In order to establish the time at which peak levels of PRL were reached, blood was drawn at 15, 30, 60, 120 and 180 min after the start of suckling in five women. Estimation of PRL in these samples showed that maxium levels of PRL were reached in $30 \mathrm{~min}$ after the start of suckling (Fig.1). It was therefore decided that blood samples for peak PRL determination would be collected $30 \mathrm{~min}$ after the start of suckling. All the samples were collected between 09.00 and 11.30 hours in order to avoid diurnal variations.

The blood samples were centrifuged, plasma separated and the samples stored at $-20^{\circ}$ until they were analysed. Serum PRL levels were estimated by a standard radioimmunoassay procedure using highly-purified human PRL 75-504 (provided by National Institute of Medical Research, Hampstead Laboratories, London). The activity was $32.5 \mathrm{mU} / \mu \mathrm{g}$ (Sinha et al. 1973). In view of the wide scatter of values, geometric means were calculated. Analysis 


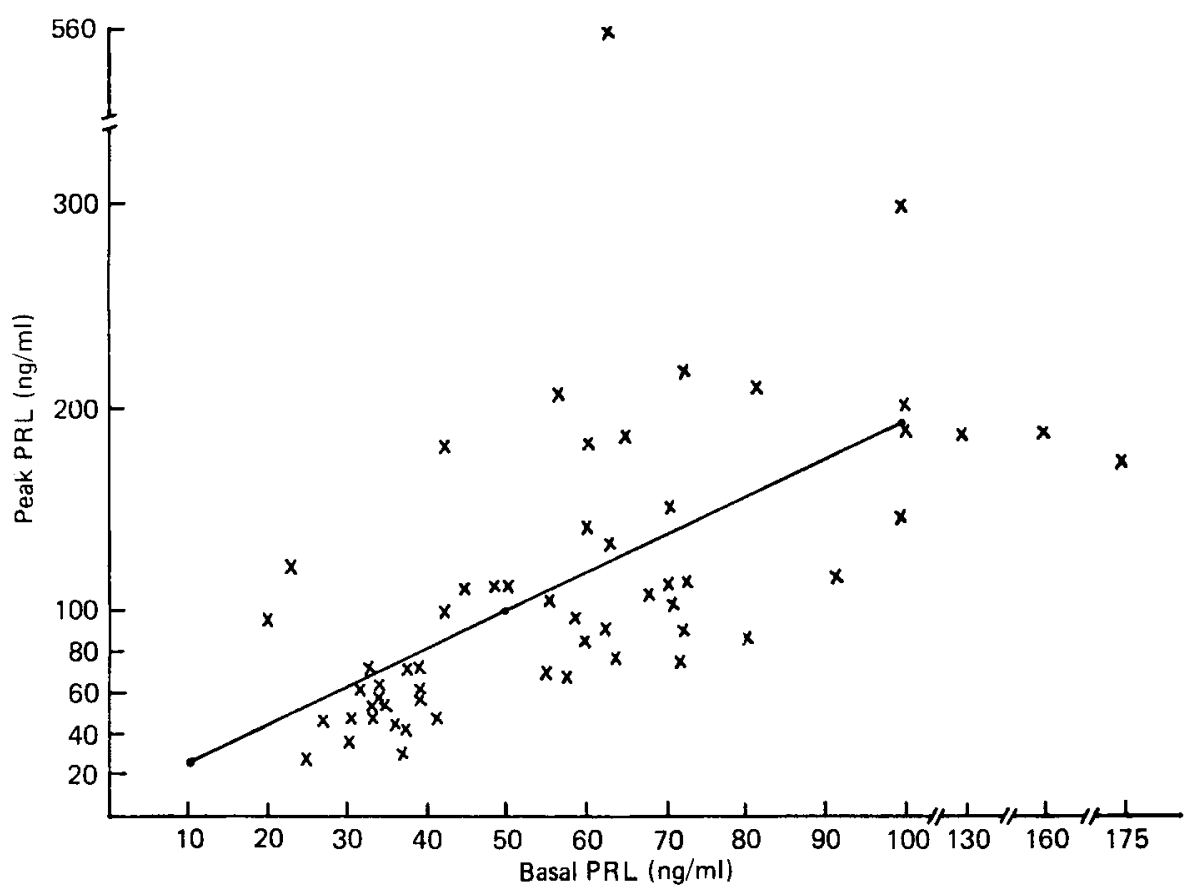

Fig. 2. Correlation between basal and post-suckling peak prolactin (PRL) levels (ng/ml) at different stages of lactation in undernourished Indian women. Regression equation: $Y=1 \cdot 86 X+6 \cdot 61$.

of variance was used to indicate differences between groups after log transformation of the values.

\section{RESULTS}

The mean ( $\pm \mathrm{SE}$ ) basal serum PRL values of all the mothers irrespective of the duration of lactation and menstrual status was $59 \cdot 1 \pm 5 \cdot 27 \mathrm{ng} / \mathrm{ml}$. The mean $( \pm \mathrm{SE})$ post-suckling peak value was $116 \cdot 7 \pm 14 \cdot 28 \mathrm{ng} / \mathrm{ml}$ which was significantly higher than the basal level $(P<0.001)$. There was a significant positive correlation between the basal PRL levels and the post-suckling peak values $(r 0.69, P<0.001$; Fig. 2 ).

The mean basal and peak PRL values in relation to duration of lactation from 1 month to 12 months in fifty-seven women is shown in Table 1 . The results show that basal values were significantly higher in all lactating women, irrespective of the duration of lactation as compared to the non-pregnant and non-lactating women $(P<0.001)$. The high basal PRL levels were maintained throughout the 12 months of lactation.

A paired $t$ test was carried out to see whether suckling induced a significant PRL response. It was found that the peak PRL levels were higher than their corresponding basal values up to 8 months of lactation, after which suckling no longer elicited a significant response (Table 1).

In women who had resumed menstruation, both the basal and peak PRL levels tended to be lower than in women who were amenorrhoic, irrespective of the duration of lactation (Table 2); however, these differences were not statistically significant. The highest peak PRL levels were seen at less than 3 months in amenorrhoic women $(P<0.05)$. Irrespective of the duration of lactation, basal PRL levels were significantly lower $(P<0.05$; Table 3$)$ 
Table 1. Serum prolactin levels $(\mathrm{ng} / \mathrm{ml})$ in relation to the duration of lactation in undernourished Indian women

(Mean values with their standard errors)

\begin{tabular}{|c|c|c|c|c|c|c|c|}
\hline \multirow{3}{*}{$\begin{array}{l}\text { Duration of } \\
\text { lactation } \\
\text { (months) }\end{array}$} & \multirow{3}{*}{$\begin{array}{l}\text { No. of } \\
\text { subjects }\end{array}$} & \multirow{2}{*}{\multicolumn{2}{|c|}{ Basal (B) }} & \multirow{2}{*}{\multicolumn{2}{|c|}{ Peak (P) }} & \multicolumn{2}{|c|}{$\begin{array}{l}\text { Statistical significance } \\
\text { of difference between }\end{array}$} \\
\hline & & & & & & \multirow{2}{*}{$\begin{array}{c}\mathrm{B} \text { and } \mathrm{P} \\
P\end{array}$} & \multirow{2}{*}{$\begin{array}{c}\text { B and NPNL } \\
P\end{array}$} \\
\hline & & Mean & $\mathrm{SE}$ & Mean & $\mathrm{SE}$ & & \\
\hline $\begin{array}{l}\text { Non-pregnant, } \\
\text { non-lactating }\end{array}$ & (7) & $19 \cdot 5$ & $1 \cdot 65$ & - & - & - & - \\
\hline$<2$ & (11) & $49 \cdot 4$ & $5 \cdot 57$ & $139 \cdot 2$ & $39 \cdot 40$ & $<0.05$ & $<0.001$ \\
\hline $3-4$ & (19) & $52 \cdot 1$ & 4.72 & $101 \cdot 3$ & 14.31 & $<0.001$ & $<0.001$ \\
\hline $5-6$ & (9) & $61 \cdot 4$ & $11 \cdot 15$ & 107.7 & 19.51 & $<0.001$ & $<0.001$ \\
\hline $7-8$ & (6) & $50 \cdot 0$ & $8 \cdot 17$ & $102 \cdot 2$ & $17 \cdot 16$ & $<0.001$ & $<0.001$ \\
\hline $9-10$ & (8) & $52 \cdot 1$ & 4.31 & 77.9 & 15.14 & NS & $<0.001$ \\
\hline $11-12$ & (4) & $43 \cdot 3$ & $6 \cdot 11$ & $64 \cdot 8$ & $16 \cdot 41$ & NS & $<0.001$ \\
\hline
\end{tabular}

NS, not significant.

in mothers whose infants were being supplemented than in those whose infants were entirely breast-fed.

The basal PRL levels were, however, not significantly different between mothers weighing less than $45 \mathrm{~kg}$ and those who weighed more (Table 4).

\section{DISCUSSION}

Results from the present study indicate that both basal and peak plasma PRL levels continue to remain at a higher level in lactating Indian women from low-income groups for at least 12 months. Similar persistence of high plasma PRL levels has been reported from developing countries of Africa (Delvoye et al. 1978; Lunn et al. 1980). In marked contrast to this finding, most of the results from developing countries indicate that the mean plasma PRL levels in lactating women reach values similar to those seen in NPNL women at approximately the third month of lactation (Tyson et al. 1972; Lunn et al. 1980). However, Tyson et al. (1978) in their later report did find high serum PRL levels after 1 year in a small group of lactating women. Suckling frequency and changing breastfeeding practices might be factors responsible for this difference. High plasma PRL levels in lactating women in developing countries may be due to the frequent suckling on demand feeding, leading to a sustained PRL stimulus.

It has been suggested that a high plasma PRL value might be one of the factors responsible for a preferential transfer of nutrients into milk in undernourished women, a mechanism evolved over millenia to ensure infant survival (Lunn et al. 1980). However, the role of elevated plasma PRL levels in well-nourished women as reported by Tyson $e t$ al. (1978) is not clear. It is also possible that persistent high PRL levels may have an anabolic role, and prevent deterioration in maternal nutritional status during lactation in undernourished women (Prema, Naidu et al. 1981). The persistently elevated plasma PRL levels might also be a protective mechanism that prolongs the duration of relative infertility during lactation, and prevents early advent of the next pregnancy with all its adverse effects on maternal and child health. Calculation of mean basal and peak plasma PRL levels in relation to return of menstruation showed that both were lower in menstruating women irrespective of the duration of lactation, but the differences were not statistically significant. 


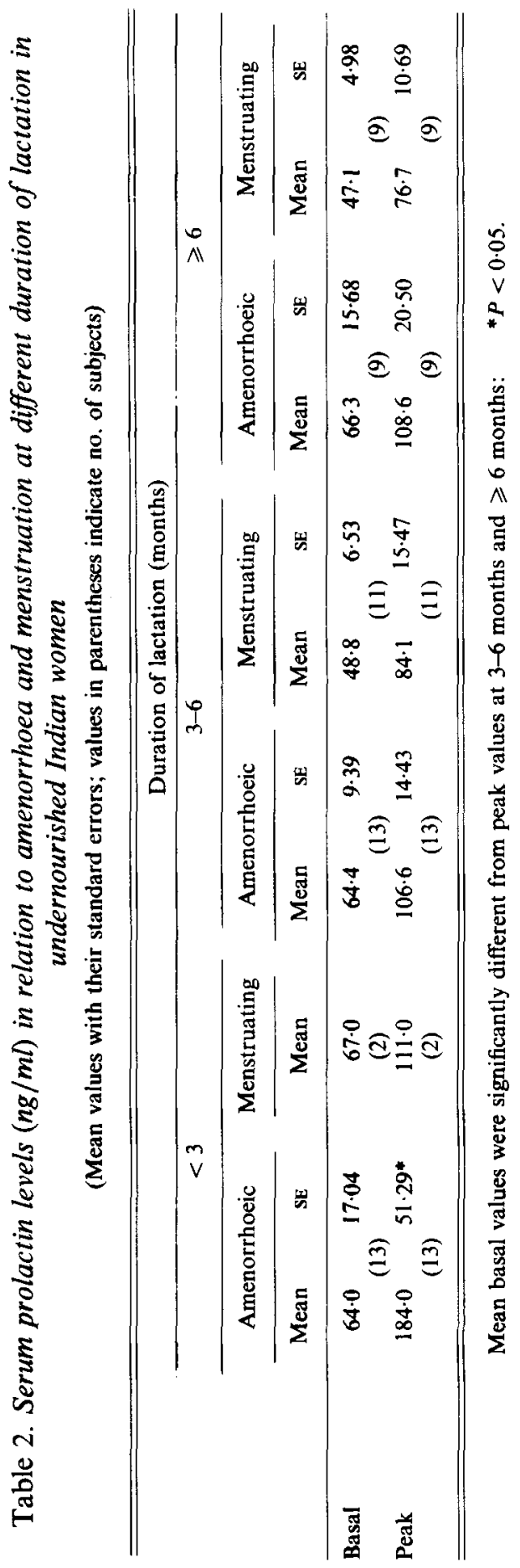


Table 3. Basal prolactin levels $(\mathrm{ng} / \mathrm{ml})$ according to lactation period and introduction of supplements to the child in undernourished Indian women

(Mean values with their standard errors; values in parentheses indicate no. of subjects)

\begin{tabular}{|c|c|c|c|c|c|c|c|c|}
\hline & \multicolumn{6}{|c|}{ Duration of lactation (months) } & & \\
\hline & \multicolumn{2}{|c|}{$<3$} & \multicolumn{2}{|c|}{$3-6$} & \multicolumn{2}{|c|}{$\geqslant 6$} & \multicolumn{2}{|c|}{ Total } \\
\hline & Mean & $\mathrm{SE}$ & Mean & $\mathrm{SE}$ & Mean & SE & Mean & $\mathbf{S E}$ \\
\hline Supplemented & \multicolumn{2}{|c|}{$(6)$} & \multicolumn{2}{|c|}{ 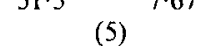 } & \multicolumn{2}{|c|}{$43 \cdot 0$} & \multicolumn{2}{|c|}{ (22) } \\
\hline Non-supplemented & $67 \cdot 6$ & $12 \cdot 84^{*}$ & $63 \cdot 5$ & $8 \cdot 37^{*}$ & $79 \cdot 5$ & $18 \cdot 63^{*}$ & $67 \cdot 7$ & $6 \cdot 59^{*}$ \\
\hline
\end{tabular}

Mean values for non-supplemented group were significantly different from those for the supplemented group: $* P<0.05$.

Table 4. Basal prolactin levels $(\mathrm{ng} / \mathrm{ml})$ according to weight and lactation period in undernourished Indian women

(Mean values with their standard errors; values in parentheses indicate no. of subjects)

\begin{tabular}{|c|c|c|c|c|c|c|c|c|}
\hline \multirow[b]{3}{*}{$W t(k g)$} & \multicolumn{6}{|c|}{ Duration of lactation (months) } & & \\
\hline & \multicolumn{2}{|c|}{$<3$} & \multicolumn{2}{|c|}{$3-6$} & \multicolumn{2}{|c|}{$\geqslant 6$} & \multicolumn{2}{|c|}{ Total } \\
\hline & Mean & SE & Mean & SE & Mean & SE & Mean & SE \\
\hline \multirow[t]{2}{*}{$\geqslant 45$} & $58 \cdot 0$ & 6.81 & $48 \cdot 8$ & $5 \cdot 15$ & $60 \cdot 5$ & $13 \cdot 08$ & $56 \cdot 2$ & $6 \cdot 25$ \\
\hline & \multicolumn{2}{|c|}{ (5) } & \multicolumn{2}{|c|}{ (7) } & \multicolumn{2}{|c|}{ (8) } & \multicolumn{2}{|c|}{ (20) } \\
\hline$<45$ & $60 \cdot 3$ & $12 \cdot 67$ & $66 \cdot 0$ & $9 \cdot 22$ & $56 \cdot 9$ & $11 \cdot 29$ & $61 \cdot 7$ & 6.09 \\
\hline
\end{tabular}

Much information exists indicating that plasma PRL levels are one of the critical determinants of return of menstruation and fertility in lactating women (Delvoye et al. 1978; McNeilly, 1979). The reason for the lack of such a correlation between return of menstruation and plasma PRL levels in this population is not obvious. Other endocrine factors that might be associated with the return of menstruation in women, despite high plasma PRL concentrations, need to be investigated.

Irrespective of duration of lactation, women whose infants were entirely breast-fed had higher plasma PRL levels than those whose infants were receiving supplements. It is well known that suckling frequency and duration of suckling are important determinants of plasma PRL levels (McNeilly, 1979).

It is possible that introduction of supplements results in shorter duration of suckling or reduced number of suckling episodes but information regarding these aspects were not obtained from the study group. In the population group studied, duration of unsupplemented lactation was found to be the major factor determining the duration of lactational amenorrhoea (Prema \& Ravindranath, unpublished results). Results of the present study suggest that this effect may have been mediated through PRL. It is often suggested that supplements need to be introduced to infants by the age of 3 months in order to prevent the fall in growth rate observed among infants in poorer segments of the population. The dangers of this are the early weaning diarrhoea in the child due to unhygienic environmental 
conditions and, for the mother, a faster return of fertility and the early advent of the next pregnancy with its attendant social, nutritional and health hazards for both mother and the infant. Therefore the introduction of early supplements to infants in isolation, with all the other disadvantages, could lead to serious repercussions in these communities.

Studies conducted from this Institute have shown that duration of lactational amenorrhoea is longer in women whose body-weights are low (Prema, Naidu et al. 1981). Studies from The Gambia have shown that duration of lactational amenorrhoea is longer during the wet season when dietary intakes are reduced. This work also showed that plasma PRL levels are high in the wet season (Whitehead et al. 1978; Lunn et al. 1980) but supplementing the mothers results in a marked reduction in plasma PRL levels. However, results of the present study showed that there were no correlations between plasma PRL levels and body-weight.

Dietary intake and body-weight are indices of nutritional status, that do not necessarily measure the same aspects of nutrition. The findings from the Gambian study, that food supplements do not result in any increase in body-weight, suggest that dietary intake and body-weight need not necessarily go together. It is possible that the effect of dietary intake on lactational amenorrhoea might have been mediated through PRL. However, the results from the present study suggest that the effect of body-weight on lactational amenorrhoea is not mediated through PRL. There is no correlation between plasma PRL levels and maternal body-weights. The reason for the differences between these studies is not obvious. It is also possible that the effect of maternal body-weight on the duration of lactational amenorrhoea might have been mediated by factors other than PRL. Studies on the pharmacokinetics of contraceptive steroids in undernourished women in Hyderabad have demonstrated that in thinner women the half-life of ingested steroids is reduced because they tend to excrete steroids faster (Prasad et al. 1979). It is possible that a similar mechanism might operate with respect to endogenous steroids and account for the delay in the return of fertility during lactation in undernourished women. Further studies on hypothalamic pituitary ovarian axis are needed to substantiate these hypotheses.

The authors are grateful to Dr S. G. Srikantia, former Director and Dr P. G. Tulpule, Director, National Institute of Nutrition for their keen interest. They acknowledge the statistical advice given by Mr Radhiah and Mr T. Ramnath. Mr Soma Raju provided excellent technical support.

Human prolaction for iodination, and antibody were gifts from NIAMDD.

\section{REFERENCES}

Bonte, M. \& Van Balen, H. (1969). J. Biol. Soc. sci. 1, 97.

Chen, L. C., Ahmed, S., Gesche, M. \& Mosley, W. H. A. (1974). Pop. Stud. 28, 277.

Delvoye, P., Badawi, M., Demaegd, M. \& Robyn, C. (1978). In Progress in Prolactin Physiology and Pathology, p. 213 [C. Robyn and M. Harter, editors]. Amsterdam: Elsevier/North Holland Biomedical Press.

Gioiosa, R. (1955). Am. J. Obstet. Gynec. 70, 162.

Lunn, P. G., Prentice, A. M., Austin, S. \& Whitehead, R. G. (1980). Lancet i, 623.

McNeilly, A. S. (1979). Br. med. Bull. 35, 151.

Perez, A., Vela, P., Masnick, G. S. \& Potter, R. G. (1972). Am. J. Obstet. Gynec. 114, 1041.

Population Reports. (1975). Pop. Rep. Ser. J. no. 4.

Prasad, K. V. S., Rao, B. S. N., Sivakumar, B. Prema, K. (1979). Contraception. $20,77$.

Prema, K., Madhavapadi, R. \& Ramalakshmi, B. A. (1981). Nutr. Rep. Intr. 24, 893.

Prema, K., Naidu, A. N. \& Neelakumari, S. (1979). Am. J. clin. Nutr. 32, 1298.

Prema, K., Naidu, A. N., Neelakumari, S. \& Ramalakshmi, B. A. (1981). Br. J. Nutr. 45, 461.

Sinha, Y. N., Selby, F. W., Lewis, U. J. \& Vanderlaan, W. P. (1973). J. Clin. Endocr. Metab. $36,509$.

Tyson, J. E., Carter, J. N., Andreassen, B., Huth, J. \& Smith, B. (1978). Fert. Ster. $30,154$.

Tyson, J. E., Hwang, P., Guyda, H. \& Friesen, H. G. (1972). Am. J. Obstet. Gynec. 113, 14.

Whitehead, R. G., Rowland, M. G. M., Hutton, M., Prentice, A. M., Muller, E. \& Paul, A. (1978). Lancet ii, 178. 